\title{
Estudo de melhoramento de solo com utilização de resíduo de indústria de celulose
}

\author{
Soil improvement study using a pulp industry waste
}

\section{Erismar Silva Maia}

erismar.maia@yahoo.com.br Instituto Federal do Ceará

Maximiliano Moreira de Sousa max_moreira@hotmail.com Instituto Federal do Ceará

Marco Fabio Porto de Aguiar marcosfpa@hotmail.com Universidade de Fortaleza Instituto Federal do Ceará

\section{Francisco Heber}

Lacerda de Oliveira heberoliveira@unifor.br Universidade de Fortaleza

\begin{abstract}
Resumo
Este artigo trata da análise de melhoramento das características mecânicas de um solo com a utilização de resíduo industrial de fábrica de celulose conhecido como Grits, sendo verificado a sua aplicação na estabilização de um solo para uso em camadas de sub-base ou base de pavimentos rodoviários. Foram estudadas quatro situações, considerando o solo sem adição de outro material e com três situações de misturas diferentes com Grits, considerando a massa de solo seco, nas proporções de $5 \%, 10 \%$ e $20 \%$, sendo 3 amostras para cada ensaio, totalizando 12 amostras por situação estudada. Foram realizados ensaios de caracterização da mistura de solo e do solo argiloso. Fez-se também um comparativo dos resultados dos ensaios de resistência mecânica obtidos com as amostras de solos e mistura solo-Grits. Diante dos resultados, em particular do Índice de Suporte Califórnia (ISC), observou-se que o Grits aumentou gradativamente a resistência do solo, principalmente na mistura de $20 \%$, apresentando valores satisfatórios para utilização em sub-base, de acordo com DNIT (2006)
\end{abstract}

Palavras-chave: Grits; Resíduos; Construção; Rodoviária; Melhoramento de solos.

\begin{abstract}
This paper presents the study that evaluates, by mechanical characterization, the soil improvement using industrial residue of pulp mill known as Grits, which has verified its application in the stabilization of soil layers for use in base or under base of road pavements. Four different mixtures using Grits were prepared on the mass of dry soil in proportions of $0 \%, 5 \%, 10 \%, 20 \%$ divided into three samples for each mixture, totaling 12 samples. Characterization tests were performed on the soil mixtures and on clayed soil. There was also a comparison of the results of mechanical resistance tests obtained with samples of soils and with soil-Grits mixture. From the results, particularly California Bearing Ratio - CBR (Indice de Suporte California - ISC, in Brazil), was inferred that the Grits gradually had increased soil resistance, mainly in the mixture of $20 \%$, satisfactory values for use in sub-base of pavement, according to DNIT (2006).
\end{abstract}

Keywords: grits; waste; construction; bus Station; Soil improveme.

\section{Introdução}

O crescimento econômico brasileiro leva o governo a investir na construção e manutenção de rodovias. A necessidade de deslocamento rápido e seguro tem sido assunto ao qual foi dedicado muito tempo e recursos. Essa demanda, dominada pela economia e pela preocupação com as questões ambientais, aliada ao desenvolvimento de transportes, leva a uma racionalização dos materiais utilizados nas camadas construtivas do pavimento, obrigando os construtores a buscarem soluções de baixo custo, acompanhadas de responsabilidade socioambiental.

Neste trabalho, o resíduo ou subproduto industrial, que é o resíduo da indústria de celulose denominado Grits, apresenta-se como um forte aliado na tentativa de se encontrar uma alternativa técnica de baixo custo para reduzir de maneira satisfatória o custo das obras de construção e recuperação de rodovias.

O Grits é um resíduo sólido, de coloração acinzentada e granulometria diversificada. Apresenta em sua composição química cerca de $20 \%$ de cálcio, dos quais $42 \%$ se encontram na forma de óxido de cálcio $(\mathrm{CaO})$, que é um componente 
significativo para a estabilização de solos. É gerado no processo de recuperação da soda cáustica, durante o cozimento da madeira de eucalipto, na indústria de celulose (MACHADO et al., 2003).

\section{Estabilizações de Solos}

A estabilização de um solo consiste em dotá-lo de condições para resistir à deformação e ruptura durante o período em que estiver exercendo funções que exigem essas características, num pavimento ou em outra obra qualquer (SENÇO, 1997).

Basicamente, os solos podem ser estabilizados de duas formas: granulométrica e quimicamente. No que diz respeito à estabilização de solos granulometricamente, destaca-se a alteração das propriedades dos solos através da adição ou retirada das partículas de solo. Esse método consiste, basicamente, na mistura de um solo com britas de rocha ou ainda mistura de dois ou mais solos visando obter um material que se enquadre em uma determinada especificação. As camadas puramente granulares, importantes em pavimentos, são sempre flexíveis e são estabilizadas granulometricamente pela compactação de um material ou mistura de materiais que apresenta uma granulometria apropriada e índices geotécnicos específicos fixados em especificações e normas vigentes (SANTANA, 1992).

Tal procedimento visa suprir a escassez de material que atenda às necessidades de projeto, alguns materiais alternativos estão sendo cada vez mais utilizados na estabilização granulométrica, como a escória de alto forno, a argila calcinada e outros materiais reciclados.

A estabilização de solos com aditivos químicos consiste em dotá-lo de condições de resistir a deformações e ruptura visando melhorar as suas características mecânicas e o seu comportamento normalmente sob a ação da água durante o período em que estiver exercendo funções que exigem essas características (SENÇO, 2007). Os materiais normalmente empregados são cimento, cal e betume.

\section{Resíduo de Fábrica de Celulose - Grits}

É um resíduo sólido, de coloração acinzentada e granulometria diversificada. De acordo com a caracterização química efetuada por Machado et al. (2003), o Grits apresenta em sua composição química cerca de $20 \%$ de cálcio, dos quais mais de $40 \%$ encontram-se na forma de óxido de cálcio $(\mathrm{CaO})$. A Figura 3.1 mostra a estrutura, numa visão microscópica, do resíduo Grits.

Figura 3.1: Foto microscópica do resíduo Grits (CETIND, 2009)

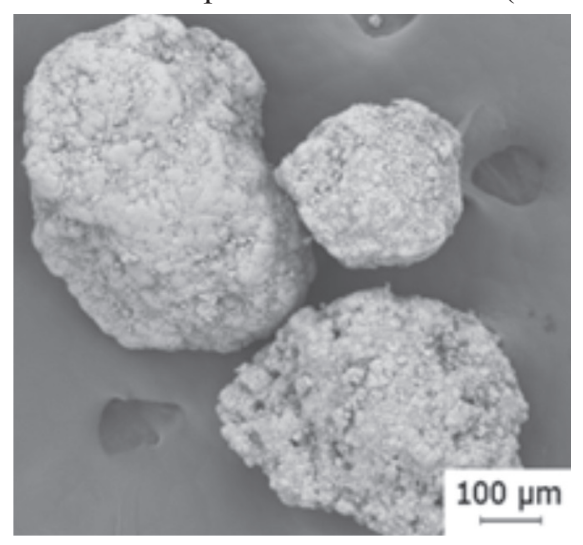

De acordo com o CETIND (2009) e a ABNT (2004), foi possível a identificação do resíduo. A composição química do Grits é basicamente oxido de cálcio $(\mathrm{CaO})$, como se observa na Tabela 3.1. 
Tabela 3.1: Composição química do resíduo Grits

\begin{tabular}{c|c}
\hline Composição & $\mathbf{( \% )}$ \\
\hline $\mathrm{CaO}$ & 96,80 \\
\hline $\mathrm{SO}_{3}$ & 1,49 \\
\hline $\mathrm{K}_{2} \mathrm{O}$ & 1,37 \\
\hline $\mathrm{SrO}$ & 0,22 \\
\hline $\mathrm{Fe}_{2} \mathrm{O}_{3}$ & 0,11 \\
\hline
\end{tabular}

\subsection{Processo Produtivo da Indústria de Celulose}

O processo Kraft (ou sulfato) é o mais utilizado mundialmente na produção de celulose. Esse processo reutiliza grande parte dos reagentes empregados no cozimento da madeira, através de uma série de operações unitárias. Uma das etapas de recuperação é a caustificação, na qual é produzido o resíduo denominado Grits e que se constitui no principal ponto de purga de elementos não processáveis (GULLICHEN; FOGELHOLN, 2000).

Durante o cozimento, as fibras de celulose são separadas da lignina e resinas, quando, então, obtém-se celulose não branqueada, formando uma polpa. A polpa resultante no processo Kraft é escura, e conforme a finalidade a que se destina, necessita de branqueamento para ser comercializada como celulose branqueada. Sendo assim, a polpa obtida no digestor é enviada para a seção de lavagem (difusor), na qual são retirados os produtos químicos utilizados e compostos orgânicos dissolvidos. A polpa lavada é conduzida a uma etapa de depuração (peneiramento), em que se tem a retirada de nós, cavacos não cozidos, feixes de madeira e impurezas normais ao processo (areia e outros) e o engrossamento da massa.

$\mathrm{Na}$ etapa de branqueamento, o licor verde clarificado é bombeado ao apagador de cal, no apagador de cal (extintor) é dosada a uma taxa calculada misturando-se ao licor verde carbonato de sódio com sulfeto de sódio $\left(\mathrm{NaCO}_{3}+\mathrm{Na}_{2} \mathrm{~S}\right)$ e formando o licor branco, hidróxido de sódio com sulfeto de sódio $\left(\mathrm{NaOH}+\mathrm{Na}_{2} \mathrm{~S}\right)$ e a lama de cal em carbonato de cálcio $\left(\mathrm{CaCO}_{3}\right)$, essa lama é convertida em cal $(\mathrm{CaO})$ com liberação de dióxido de carbono $\left(\mathrm{CO}_{2}\right)$, como mostra a Figura 3.2. A cal não reagida sedimenta-se no classificador sendo então empurrada para fora do extintor. Esse resíduo é conhecido como Grits.

Figura 3.2: Esquema simplificado do processo Kraft na produção de celulose (SMOOK, 1989)

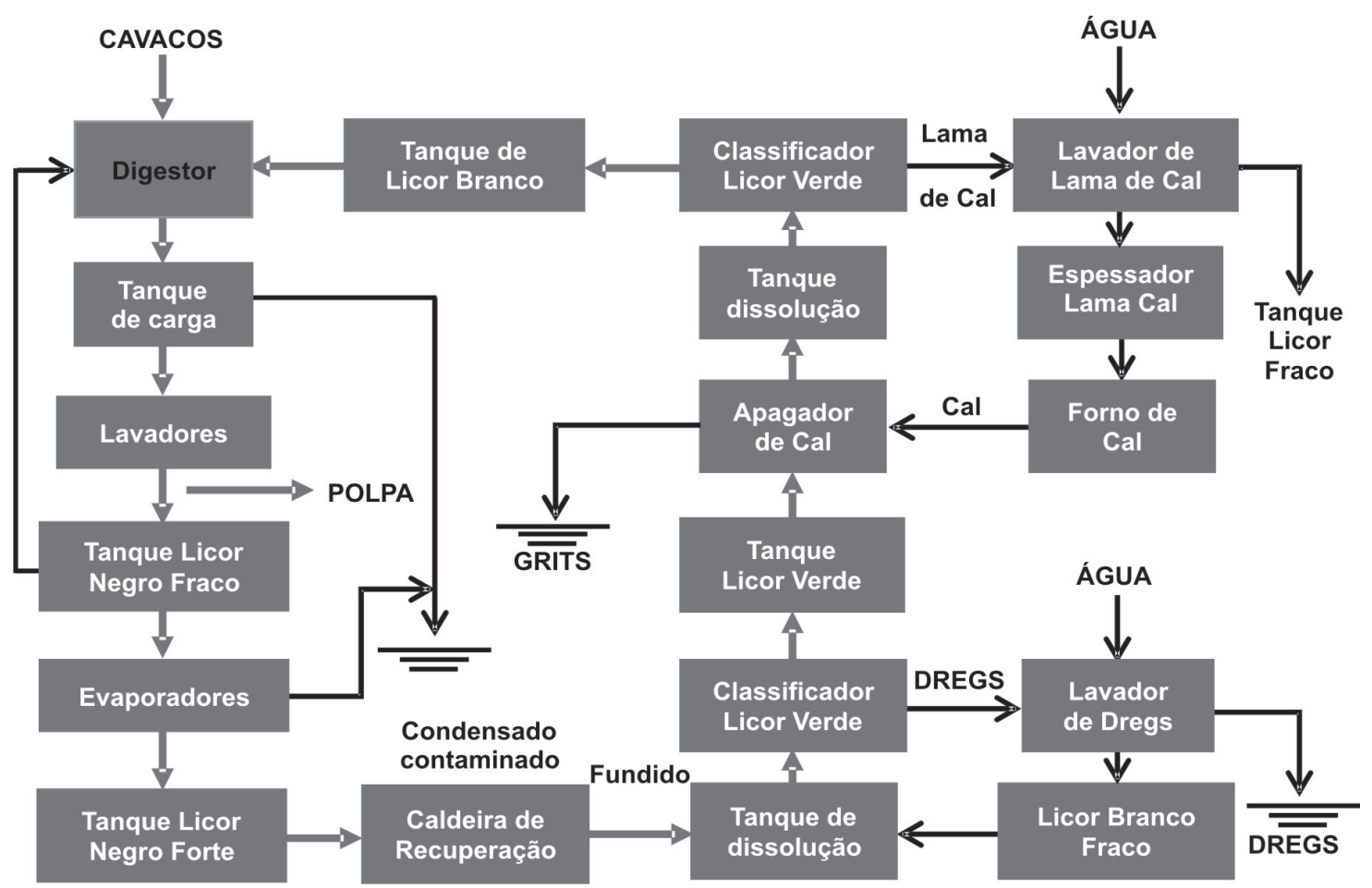


No processo Kraft de fabricação de celulose, podem ser gerados outros resíduos, juntos ou separados, dependendo da característica de cada unidade fabril, a qual também pode apresentar subprocessos específicos que alteram a qualidade final desses resíduos.

\subsection{Aplicação de Solos-Grits em Camadas de Pavimentos}

Rezende (2003) avaliou que, a partir do processo Kraft, o material residual de granulometria variada Grits, além de apresentar boa resistência mecânica, sua característica granulométrica pode caracterizá-lo como arenopedregulhoso, de acordo com a ABNT (1995). Isso facilita o seu estudo quando associado ao solo, pois a análise granulometria é parâmetro fundamental na caracterização do material, com vistas a prever seu eventual comportamento nas obras de pavimentos. O resíduo industrial de fábrica de celulose, conhecido como Grits, é um material que apresenta alta densidade, rigidez e resistência, possuindo um aspecto similar em sua granulometria a outros agregados com mesmo desempenho e baixo custo (PEREIRA, 2006).

Pereira (2005) também avaliou as características relacionadas ao comportamento de dois solos não recomendados à execução de obras rodoviárias, em particular as camadas de reforço de subleito, quando submetidos à mistura de um material residual Grits. Foram realizados ensaios de granulometria utilizando dois solos selecionados para a composição das misturas denominados respectivamente de Solo 1 e Solo 2. Esses solos possuem curvas granulométricas semelhantes e situam-se em classes coincidentes, segundo a classificação pela Transportation Research Board (TRB). Essa classificação utilizada no meio rodoviário, dentre outros parâmetros, baseia-se na granulometria do solo, tendo como indicativo de comportamento do solo as quantidades de material que passam na peneira de $\mathrm{n}^{\circ} 200(0,075 \mathrm{~mm})$.

O Solo 1, que no seu estado natural apresentou características de solos finos e, dessa forma, não recomendados para a utilização como material de construção na execução dos tipos de obras mencionados anteriormente, mostrou-se com características granulométricas próximas dos patamares recomendados pelo TRB, após o acréscimo de 15\% de Grits.

O Solo 2 que, assim como o Solo 1, também apresentou características granulométricas de solos finos no seu estado natural, mostrou-se mais indicado à execução das obras rodoviárias após o acréscimo de $24 \%$ do mesmo resíduo Grits. Segundo a classificação rodoviária do TRB, essa mistura apresenta indícios de bom comportamento nesses tipos de obras. A ideia de se utilizar o Grits, como mistura em solos, baseia-se no resultado da análise granulométrica após a mistura, de maneira que possa identificar o resultado obtido dentro de um grupo de materiais que apresentem comportamentos semelhantes, sob o ponto de vista dos aspectos construtivos da sua utilização em obras rodoviárias.

Pereira et al. (2006) analisaram as propriedades mecânicas do resíduo Grits, como também outros resíduos de celulose, com o objetivo de contribuir para a reciclagem dos dejetos provenientes de resíduos sólidos industriais. Os materiais foram separados por tipos e, em seguida, lavados e secos. Foram avaliados quanto à densidade, pureza, propriedades mecânicas e termomecânica. A partir da avaliação dos resultados obtidos com o Grits, concluiu-se que eles apresentam boas propriedades com vantagem de serem mais resistentes à tração, podendo ser utilizados como agregado em diversas aplicações. Reforçaram que a necessidade de utilização contínua de recursos naturais (solo) implica na busca de novos materiais para utilização, se não ao todo, mas ao menos uma parcela do total utilizado numa obra. Os resultados deste trabalho mostram que um material de construção natural não recomendado à utilização em obras rodoviárias apresenta indícios de bom comportamento após sua mistura com um resíduo sólido Grits.

Esses resultados mostram que a ideia de desenvolvimento sustentável, a qual, pelo ponto de vista da engenharia, envolve o uso e produção de materiais que apresentem maior tempo de vida útil, com menor impacto ambiental, é possível, bem como a utilização de resíduos urbanos e industriais, reduzindo o consumo de recursos naturais e da energia empregada para obter ou produzir os materiais a serem empregados, reduzindo assim a poluição gerada.

\section{Metodologia}

Para a realização dos ensaios laboratoriais, foi selecionado e coletado uma amostra de solo, tipo areia com finos (argila e silte) e pedregulho. Sua manifestação é bem representativa no estado do Ceará, sendo coletado de uma jazida próxima ao anel viário de Fortaleza, no bairro Pedras, localizado na latitude $3^{\circ} 52^{\prime} 12.73$ ”S e longitude $38^{\circ} 31^{\prime} 59.40^{\prime \prime} \mathrm{O}$ (SIRGAS 2000). Esse solo foi escolhido por ser proposto em obras rodoviárias para camadas de base e sub-base.

O resíduo industrial Grits foi cedido pela empresa Bahia Specialty Cellulose (BSC), situado na região de Camaçari, Bahia. Trata-se de um resíduo sólido, de coloração acinzentada e granulometria diversificada, gerado na hidratação da cal 
que ocorre na recuperação da lama de cal. É constituído de impurezas que não reagiram e possui, também, quantidades de $\mathrm{CaO}, \mathrm{Ca}(\mathrm{OH})$, Na e $\mathrm{CO}$.

Com base em estudos de reutilização de resíduos na construção rodoviária, como melhorias granulares aplicados a solos, a fim de realizarmos um comparativo de desempenho, definiram-se os seguintes traços de Grits em relação à massa de solo seco: $0 \%, 5 \%, 10 \%$ e $20 \%$.

Para cada traço foram separadas três amostras de igual quantidade para garantir uma melhor confiabilidade nos resultados. A preparação das amostras para os ensaios de laboratório foi realizada seguindo os padrões descritos em DNER (1994b).

O primeiro procedimento adotado foi a coleta de solo, feita através de escavação manual com pá e picareta. Essa amostra de aproximadamente $200 \mathrm{~kg}$ foi transportada em sacos de nylon para o laboratório de mecânica dos solos do Instituto Federal do Ceara (IFCE), para ensaios.

O resíduo Grits foi coletado no contêiner que faz o transporte do resíduo do local de geração ao aterro de descarte. O resíduo sai do processo industrial numa temperatura aproximada de $45^{\circ} \mathrm{C}$ e com taxa de umidade elevada, em razão da origem do Grits, que apresenta soda cáustica $(\mathrm{NaOH})$ residual. Para o manuseio seguro da amostra de aproximadamente $200 \mathrm{~kg}$ de Grits, este foi submetido à lavagem com água corrente, até a eliminação da soda cáustica residual presente na sua superfície. Em seguida, foi secado ao ar livre e colocado em estufa a $101^{\circ} \mathrm{C}$, por 24 horas

Realizaram-se os seguintes ensaios com as amostras de solo e misturas solo-Grits: a) índice de suporte Califórnia (DNER 1994a); b) compactação utilizando amostras trabalhadas (DNER, 1994b); c) análise granulométrica (DNIT, 1994a); d) limite de plasticidade (DNIT, 1994b); e) determinação da densidade real (DNIT, 1994c); f) limite de liquidez (DNIT, 1994d); e g) classificação das amostras de solo pelo sistema Transportation Research Board (TRB)

\subsection{Ensaios de Laboratório}

A seguir, são apresentados os resultados dos ensaios de laboratório para o solo natural e para as misturas solo-Grits.

Os ensaios realizados com amostras de solo natural, isto é, sem mistura, apresentaram os resultados representados pelas médias aritméticas, mostrados nas Tabelas 4.1 a 4.4, considerando três amostras para cada ensaio: granulometria, limites de consistência, compactação e índice de suporte Califórnia.

Tabela 4.1: Granulometria do solo natural

\begin{tabular}{ccc}
\hline Peneira & Peneira & Média \\
\hline$\left(\mathrm{N}^{\circ}\right)$ & $(\mathrm{mm})$ & $(\%)$ \\
\hline $1 "$ & 25,4 & 100 \\
\hline $3 / 4 "$ & 19,1 & 98,02 \\
\hline $1 / 2 "$ & 12,9 & 92,26 \\
\hline $3 / 8^{\prime \prime}$ & 9,5 & 86,58 \\
\hline $\mathrm{N}^{\circ} 4$ & 4,8 & 77,71 \\
\hline $\mathrm{N}^{\circ} 10$ & 2,00 & 72,44 \\
\hline $\mathrm{N}^{\circ} 40$ & 0,42 & 58,64 \\
\hline $\mathrm{N}^{\circ} 100$ & 0,15 & 43,15 \\
\hline $\mathrm{N}^{\circ} 200$ & 0,074 & 36,31 \\
\hline
\end{tabular}

Tabela 4.2: Limites de consistência

\begin{tabular}{c|c}
\hline Parâmetro & Média \\
\hline Limite de Liquidez (LL) & $37,88 \%$ \\
\hline Limite de Plasticidade (LP) & $20,99 \%$ \\
\hline Índice de Plasticidade (IP) & $16,89 \%$ \\
\hline
\end{tabular}


Tabela 4.3: Compactação

\begin{tabular}{l|l|l}
\hline & Umidade Ótima $(\%)$ & Massa especifica $\left(\mathrm{g} / \mathrm{cm}^{3}\right)$ \\
\hline Média & 13,86 & 1,92 \\
\hline
\end{tabular}

Tabela 4.4: ISC solo natural

\begin{tabular}{l|l|l}
\hline & ISC (\%) & Expansão $(\%)$ \\
\hline Média & 7,07 & 2,65 \\
\hline
\end{tabular}

Os resultados, considerando valores médios, dos ensaios de granulometria, limites de consistência, compactação e índice de suporte Califórnia das misturas solo-Grits, respectivamente, estão representados nas Tabelas 4.5 a 4.8.

Tabela 4.5: Granulometria da mistura solo-Grits

\begin{tabular}{c|c|c|c|c}
\hline Peneira $\left(\mathrm{N}^{ }\right)$ & Peneira $(\mathrm{mm})$ & Solo-Grits $5 \%$ & Solo-Grits $10 \%$ & Solo-Grits 20\% \\
\hline $1 "$ & 25,4 & 99,38 & 99,12 & 99,96 \\
\hline $3 / 4 "$ & 19,1 & 96,47 & 95,86 & 96,82 \\
\hline $1 / 2 "$ & 12,9 & 87,09 & 84,77 & 90,29 \\
\hline $3 / 8 "$ & 9,5 & 81,47 & 81,24 & 86,15 \\
\hline $\mathrm{N}^{\circ} 4$ & 4,8 & 71,75 & 74,99 & 79,13 \\
\hline $\mathrm{N}^{\circ} 10$ & 2,00 & 67,31 & 70,81 & 73,22 \\
\hline $\mathrm{N}^{\circ} 40$ & 0,42 & 55,35 & 48,96 & 50,28 \\
\hline $\mathrm{N}^{\circ} 100$ & 0,15 & 44,60 & 32,27 & 29,85 \\
\hline $\mathrm{N}^{\circ} 200$ & 0,074 & 36,84 & 22,34 & 17,84 \\
\hline
\end{tabular}

Tabela 4.6: Resumo das medidas dos limites de consistência

\begin{tabular}{c|c|c|c}
\hline & Solo-Grits 5\% & Solo-Grits 10\% & Solo-Grits 20\% \\
\hline LL & $37,71 \%$ & $34,53 \%$ & $25,78 \%$ \\
\hline LP & $17,43 \%$ & $20,38 \%$ & $16,93 \%$ \\
\hline IP & 20,28 & $14,15 \%$ & $8,85 \%$ \\
\hline
\end{tabular}

Tabela 4.7: Resultado dos ensaios de compactação

\begin{tabular}{c|c|c}
\hline & Umidade ótima (\%) & Massa especifica $\left(\mathrm{g} / \mathrm{cm}^{3}\right)$ \\
\hline Solo & 13,86 & 1,92 \\
\hline Solo-Grits 5\% & 13,00 & 1,94 \\
\hline Solo-Grits 10\% & 13,01 & 1,95 \\
\hline Solo-Grits 20\% & 12,80 & 1,91 \\
\hline
\end{tabular}


Tabela 4.8: Resultado do ensaio de ISC

\begin{tabular}{c|c|c}
\hline & ISC (\%) & Expansão (\%) \\
\hline Solo & 7,07 & 2,65 \\
\hline Solo-Grits 5\% & 10,7 & 2,20 \\
\hline Solo-Grits $10 \%$ & 16,93 & 1,13 \\
\hline Solo-Grits $20 \%$ & 26,98 & 0,29 \\
\hline
\end{tabular}

\subsection{Análise dos Resultados dos Ensaios de Laboratório}

Neste item, são apresentadas as análises dos resultados dos ensaios de laboratório para as amostras de solo natural e para as amostras de solo-Grits.

\section{Solo Sem Mistura (Natural)}

Nas análises granulométricas das amostras, foram identificadas as percentagens de cada fração que fazia parte do solo em estudo. Tomando como base a média aritmética dos resultados de granulometria (Figura 4.1), foi observado: $22,35 \%$ de pedregulho, $40,83 \%$ de areia $(5,15 \%$ de areia grossa, $12,20 \%$ de areia media e $23,48 \%$ de areia fina) e $36,82 \%$ de finos (que passam na peneira de abertura $0,075 \mathrm{~mm}$ ).

Figura 4.1: Curva Granulométrica do solo natural

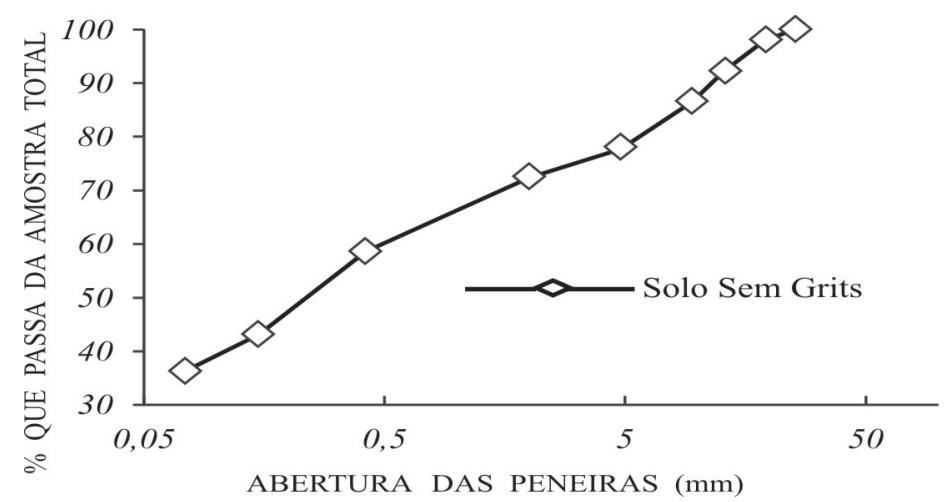

Os ensaios de limites de consistências nas três amostras do solo comprovaram a plasticidade deste, com LL variando entre $37,19 \%$ e $38,40 \%$, com média de $37,88 \%$, e o LP variando entre $22,69 \%$ e $19,63 \%$, com média de $21,00 \%$. Com esses resultados, chegou-se ao índice de plasticidade e foi calculado o índice de grupo (IG) do solo, que apresentou o mesmo resultado para as três amostras, sendo igual a 2. A densidade real do grão foi de 2,54, e o solo foi classificado de acordo com o sistema TRB como A-6, solo argiloso plástico.

O LL e IP apresentaram valores superiores ao mínimo exigido pelo DNIT (2006), não se recomendando o uso desse material em camadas de base dos pavimentos rodoviários. Porém, quando esses índices são ultrapassados, o equivalente de areia precisa ser superior a $30 \%$. O resultado apresentado para o equivalente de areia foi de $10,36 \%$, resultado que reafirma a não indicação do uso desse material em camadas de base dos pavimentos.

No ensaio de ISC, as medições de expansão foram realizadas individualmente, para cada amostra de solo, sendo utilizada, na moldagem de cada amostra, suas respectivas umidades ótimas. Os resultados do ISC variaram de $6,8 \%$ a $7,4 \%$, com média de $7,07 \%$ e expansão de $2,18 \%$ a 3,22\%, com média de $2,65 \%$. Para as três amostras de solo, o ISC foi consideravelmente baixo para a especificação de base ou sub-base, já que esse valor deve ser maior que $80 \%$ para base e maior que $20 \%$ para sub-base, de acordo com DNIT (2006). Observou-se que o solo é recomendado apenas como subleito, a expansão do solo ficou acima do exigido para uso em camadas de base ou sub-base. 


\section{Mistura Solo-Grits}

As misturas de solo-Grits foram submetidas aos mesmos ensaios realizados no solo natural. A primeira mistura, com adição de 5\% de Grits da massa de solo seco, foi classificada como pertencente ao grupo A-6 pelo sistema TRB, solo argiloso plástico. A segunda mistura realizada foi com $10 \%$, e a terceira com $20 \%$, sendo classificadas, de acordo com sistema TRB, como A-2-6 e A-2-4, respectivamente. Esses grupos abrangem materiais como pedregulho e areia grossa, cujo teor de argila plástica se assemelha com as características do grupo A-6, mas com o índice de grupo (IG) equivale a 0 (zero). A densidade real do grão foi de 2,48 para o solo A-2-6 e 2,59 para o solo A-2-4. A Tabela 4.9 mostra as classificações TRB das amostras, e a Figura 4.2 mostra as curvas granulométricas.

Tabela 4.9: Resumo da classificação das amostras

\begin{tabular}{c|c}
\hline Amostra & Classificação TRB \\
\hline Solo Natural & A - 6 \\
\hline Solo-Grits $5 \%$ & A - 6 \\
\hline Solo-Grits $10 \%$ & A - 2 - 6 \\
\hline Solo-Grits $20 \%$ & A - 2-4 \\
\hline
\end{tabular}

Figura 4.2: Granulometria das amostras

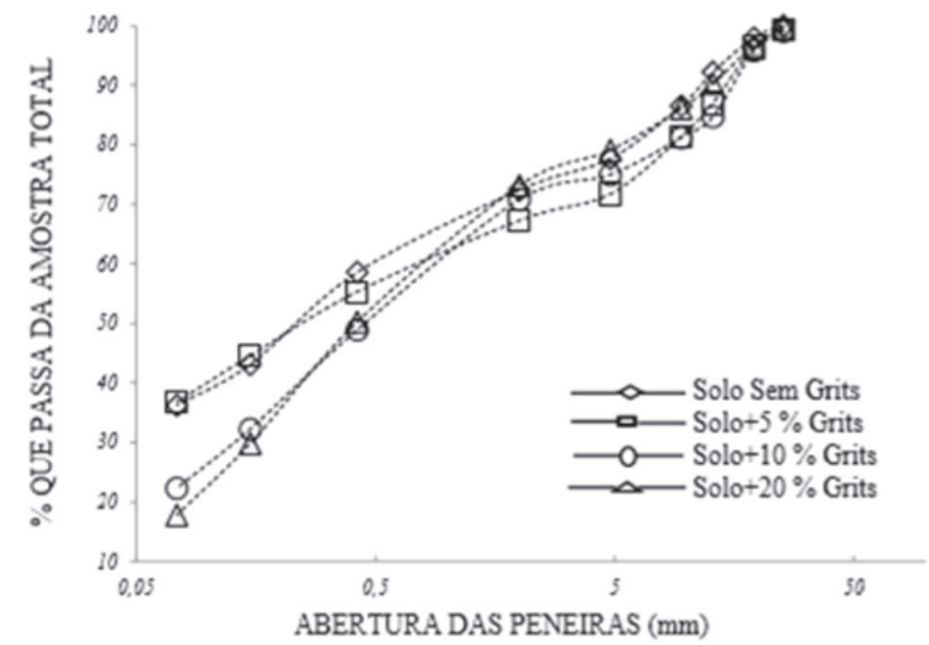

Os valores dos limites de consistência das misturas, para as amostras de solo com 5\%, 10\%, e $20 \%$ de Grits, apresentaram valores superiores aos exigidos pelo DNIT (2010b), não indicando, assim, o uso do material em camadas de base dos pavimentos rodoviários.

Nos ensaios de compactação das doze amostras de solo. Foram observados que houve uma diminuição na umidade ótima de $1,06 \%$ entre o solo natural e o solo com $20 \%$ de Grits, considerando as médias dos valores.

Os ensaios de ISC e expansão, assim como no solo natural, foram realizados individualmente para cada amostra de solo-Grits, em conformidade com os percentuais definidos de Grits e suas respectivas umidades ótimas. Os resultados do ISC variaram de 7,07\% a 26,98\% (Figura 4,2), sendo as medidas de expansões de $2.65 \%$ a $0,29 \%$, variando-se de acordo com a adição de Grits. 
Figura 4.3: Curva penetração x pressão dos ensaios ISC.

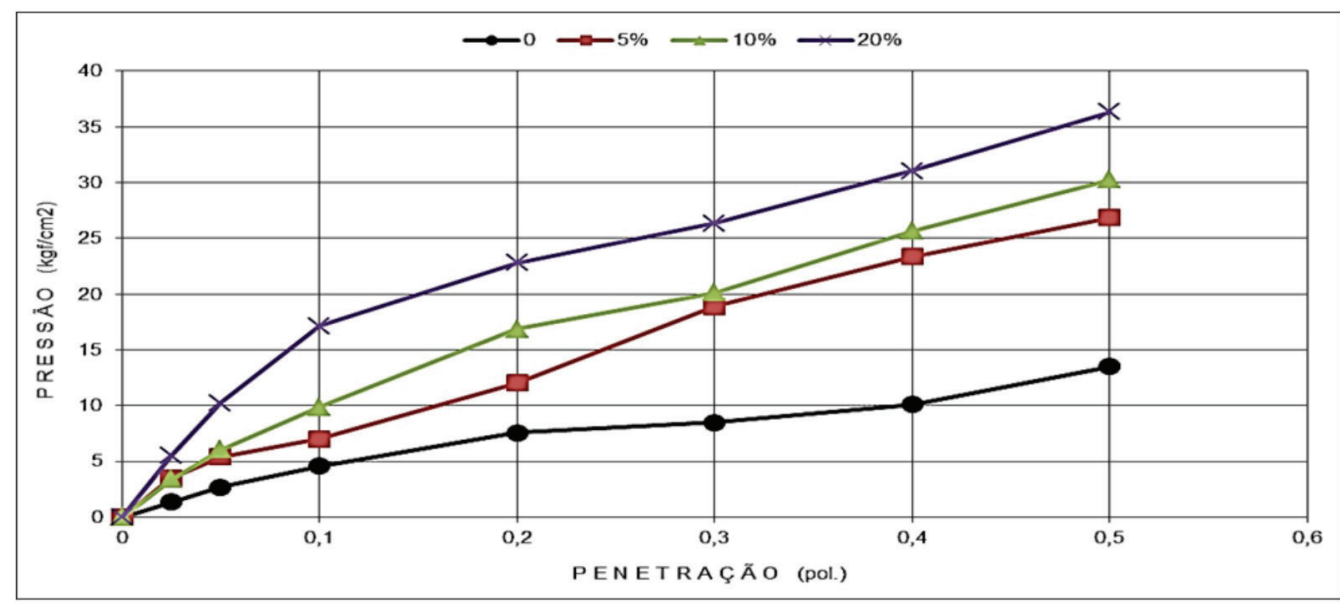

Observa-se que, com a adição gradativa de Grits, as misturas de 5\%,10\% e 20\% apresentaram resultados melhores. Com relação à mistura com $20 \%$, é aceitável a sua utilização em camadas de sub-base, pois ela apresenta valores acima de $20 \%$ para o ISC, o que é exigido nas especificações do DNIT (2006). No que diz respeito à utilização em base, ainda ficou abaixo do exigido, pois os valores devem ser maiores que $60 \%$. A expansão do solo é avaliada como aceitável para camadas de sub-base. A Tabela 4.10 mostra um quadro resumo com os principais resultados.

Tabela 4.10: Quadro resumo

\begin{tabular}{ccccccc}
\hline Material & $\mathrm{h}_{\mathrm{ot}}(\%)$ & $\gamma\left(\mathrm{g} / \mathrm{cm}^{3}\right)$ & $\mathrm{ISC}(\%)$ & $\mathrm{e}(\%)$ & $\mathrm{IP}$ & Classificação \\
\hline Solo natural & 13,86 & 1,92 & 7,07 & 2,65 & 16,90 & $\mathrm{~A}-6$ \\
\hline Solo $+5 \%$ Grits & 13,00 & 1,94 & 10,7 & 2,20 & 20,28 & $\mathrm{~A}-6$ \\
\hline Solo+10\% Grits & 13,01 & 1,95 & 16,93 & 1,13 & 14,15 & $\mathrm{~A}-2-6$ \\
\hline Solo+20\% Grits & 12,86 & 1,91 & 26,98 & 0,29 & 8,85 & $\mathrm{~A}-2-4$ \\
\hline
\end{tabular}

\section{Conclusões}

Em conformidade com os resultados dos ensaios realizados, pode-se confirmar a alteração das propriedades mecânicas do solo, submetido à analise após a adição do resíduo Grits.

O solo utilizado para as misturas, em seu estado natural, foi classificado pelo sistema TRB como pertencente ao grupo A-6, com características plásticas argilosas, e apresentou também pedregulhos em sua composição. Dessa forma, não se enquadrou em nenhuma das faixas granulométricas especificadas de acordo com o DNIT (2006), e sua baixa resistência foi comprovada com o ensaio de ISC, que em média não passou de 7,07\%. Considerando-se as características iniciais do solo, este trabalho possibilitou a visualização clara do melhoramento gradativo da resistência do solo e de seu comportamento granulométrico no decorrer dos ensaios à medida que se ia aumentando o percentual de material Grits na mistura.

Com a adição de 5\% de Grits, houve uma pequena alteração no ISC, ficando numa média de 10,70\%, permanecendo o seu enquadramento no grupo A-6 da classificação TRB, colocando-se ainda fora dos parâmetros aceitáveis de acordo com DNIT (2006). Já a mistura do solo com $10 \%$ do resíduo, foi obtida uma mudança considerável em seu comportamento e a mistura passou a se enquadrar no grupo A-2-6, comprovando valor de ISC de 17,0\%, sendo a faixa granulométrica F, o que indica uma melhoria em suas características de resistência, porém continuando fora das especificações mínimas exigidas para utilização do material nas camadas de base e sub-base. A adição de $20 \%$ de Grits ao solo, portanto, mostrouse a mais eficaz, em termos de melhorias de comportamento mecânico. A mistura se enquadrou no grupo A-2-4 e seu ISC atingiu até $27,0 \%$, com granulometria na faixa E. Os resultados indicam que, segundo os padrões de DNIT (2006), essa mistura comprovou, considerando critério de resistência e expansão, parâmetros suficientes para emprego em camada de sub-base. 
A mistura solo-Grits com $20 \%$ de resíduo comprovou melhoramento do solo quanto à granulometria, resistência e expansão. Ao aumentar-se o percentual de Grits, foi possível verificar a melhoria gradativa dessas características. Com relação à plasticidade, ficou abaixo do limite recomendado para o uso em base de pavimento. No entanto, visualiza-se boa possibilidade de estudos futuros, mediante a importância ambiental do tema, pois o resíduo Grits necessita de descarte especifico em aterros sanitário ou em áreas abertas e muitas vezes desmatadas apenas para esse fim. A utilização do resíduo Grits como estabilizante de solos aplicado à construção rodoviária é possível. Indica-se, ainda, a possibilidade da realização de outros trabalhos relacionados a essa mistura, aumentando-se o percentual de resíduo na mistura e verificando sua resistência por meio do módulo de resiliência, para a sua utilização em camadas de pavimento.

\section{Referências}

ASSOCIAÇÃO BRASILEIRA DE NORMAS TÉCNICAS. NBR 6502: rochas e solos. Rio de Janeiro, 1995. ASSOCIAÇÃO BRASILEIRA DE NORMAS TÉCNICAS. NBR 10004 a 10007: Resíduos sólidos. Rio de Janeiro, 2004.

CENTRO DE TECNOLOGIA INDUSTRIAL PEDRO RIBEIRO. Laudo técnico de classificação do resíduo solido grits oriundo do processo da indústria do ramo de papel e celulose. Salvador, 2009.

DEPARTAMENTO NACIONAL DE ESTRADAS DE RODAGEM. DNER-ME 049: Solos - determinação do índice de suporte califórnia utilizando amostras não trabalhadas - método de ensaio. Rio de Janeiro, 1994a.

DEPARTAMENTO NACIONAL DE ESTRADAS DE RODAGEM. DNER-ME 162: solos - ensaio de compactação utilizando amostras trabalhadas - método de ensaio. Rio de Janeiro, 1994b.

DEPARTAMENTO NACIONAL DE INFRAESTRUTURA DE TRANSPORTES. DNIT-ME 051: solos - análise granulométrica - método de ensaio. Rio de Janeiro, 1994c.

DEPARTAMENTO NACIONAL DE INFRAESTRUTURA DE TRANSPORTES. DNIT-ME 082: solos - determinação do limite de plasticidade - método de ensaio. Rio de Janeiro, 1994d.

DEPARTAMENTO NACIONAL DE INFRAESTRUTURA DE TRANSPORTES. Solos - determinação da densidade real - método de ensaio. Rio de Janeiro, 1994e.

DEPARTAMENTO NACIONAL DE INFRAESTRUTURA DE TRANSPORTES. DNIT-ME 122: solos - determinação do limite de liquidez - método de referência e método expedito - método de ensaio. Rio de Janeiro, 1994f.

DEPARTAMENTO NACIONAL DE INFRAESTRUTURA DE TRANSPORTES. Publicação IPR - 719: Manual de Pavimentação. Rio de Janeiro, 2006.

DEPARTAMENTO NACIONAL DE INFRAESTRUTURA DE TRANSPORTES. DNIT- ES 139: pavimentação - subbase estabilizada granulometricamente - especificação de serviço. Brasília, DF, 2010a

DEPARTAMENTO NACIONAL DE INFRAESTRUTURA DE TRANSPORTES. DNIT-ES 141: pavimentação - base estabilizada granulometricamente - especificação de serviço. Brasília, DF, $2010 \mathrm{~b}$.

GULLICHEN, J.; FOGELHOLN, C. J. Chemical pulping in papermaking science and technology. Helsinki: Fapet, 2000. $693 \mathrm{p}$.

MACHADO, C.; PEREIRA, R. S.; PIRES, J. M. M. Influência do tratamento térmico do resíduo sólido industrial (Grits) na resistência mecânica de um latossolo para pavimentos de estradas florestais. Revista Árvore, [s.1.], v. 27, n. 4, p.543-550, jul./ago. 2003.

PEREIRA, R. S.; MACHADO, C. C.; CARVALHO, C. A. B. Uso de resíduos em pavimentos de estradas florestais: caracterização de solos e misturas solo-grits. Revista Árvore, [s.1.], v. 30, n. 4, p.629-635, jul./ago. 2006.

PEREIRA, R. S. Viabilidade técnica do emprego de resíduos da indústria de celulose para construção de estradas florestais. 2005. 329 f. Tese (Doutorado em Engenharia Civil) - Faculdade de Tecnologia, Universidade Federal de Viçosa, Viçosa, 2005.

PEREIRA, R. S. et al. Uso de resíduo industrial grits em pavimentação de estradas florestais: influência do período de cura da resistência mecânica e expansão de mistura solo-grits compactado. Revista Árvore, [s.1], v. 30, n. 5, p. 795-802, set./out. 2006.

REZENDE, L. R. Estudo do comportamento de materiais alternativos utilizados em estruturas de pavimentos flexiveis. 
2003. 372 f. Tese (Doutorado em Geotecnia) - Departamento de Engenharia Civil e Ambiental, Universidade de Brasília, Brasília, 2003.

SANTANA, H. Manual de pré-misturas a frio. Rio de Janeiro: Instituto Brasileiro de Petróleo - IBP, Comissão de Asfalto, 1992.

SENÇO, W. Manual de técnicas de pavimentação. São Paulo: Pini, 1997. 746p. v.1.

SENÇO, W. Manual de técnicas de pavimentação. São Paulo: Pini, 2007. 671p. v. 2.

SIRGAS2000. Sistema de Referência Geocêntrico para as Américas. Sistema geodésico de referência oficialmente adotado no Brasil. 2000.

SMOOK, G. A. Handbook for pulp and paper technologists. 2. end, Vancouve, Canadá: Angus Wilde Publications Inc., 225p.1992.

\section{Sobre os Autores}

\section{Erismar Silva Maia}

Tecnólogo em Estradas pelo Instituto Federal de Educação, Ciência e Tecnologia do Ceará (IFCE)

Técnico em Transportes no Metrô de Fortaleza (METROFOR).

\section{Maximiliano Moreira de Sousa}

Tecnólogo em Estradas pelo Instituto Federal de Educação, Ciência e Tecnologia do Ceará (IFCE)

Aluno do curso de Especialização em Infraestrutura de Transportes | Rodovias, do Instituto Brasileiro de Educação Continuada (INBEC).

\section{Marco Fabio Porto de Aguiar}

Doutor em engenharia civil, área de concentração geotecnia, pela COPPE/Universidade Federal do Rio de Janeiro (2008), Mestre em geotecnia e Infraestrutura pela Universidade de Hannover- Alemanha (1997) e graduado em engenharia civil pela Universidade Federal do Ceará (1993), Professor da Universidade de Fortaleza (UNIFOR) e Instituto Federal do Ceará (IFCE). Consultor na área de fundações, contenções e infraestrutura de transporte.

\section{Francisco Heber Lacerda de Oliveira}

Doutorando e em engenharia civil, área de concentração engenharia de transportes, pela Universidade Federal do Ceara, Mestre em engenharia de transportes pela Universidade Federal do Ceará (2009), Professor da Universidade de Fortaleza (UNIFOR). Consultor em engenharia de transportes. 